\title{
Specificity of Chemical Constituents in Grapefruit Juice Which Are Known to Inhibit CYP3A4 Activity
}

\author{
折 井義 光* 坪 井 貴 司* 谷 河 賞 彦* \\ 橋 爪 憲 聖* 河 野 浩 一*
}

\section{Introduction}

Some flavonoids and furanocoumarins in grapefruit juice (GFJ) have been identified as CYP3A4 inhibitors ${ }^{1,2)}$. However, it has not yet been investigated whether these compounds are specific constituents only in GFJ. Therefore, quantitative comparison of these chemical constituents among GFJ, grapefruit (GF) and other citrus fruits and juices was conducted by HPLC/UV methods.

\section{Methods}

Materials:

1) GFJ: Commercially available four brands

2) GF (Citrus paradisi Macf.): Two different habitats, "white" and "ruby"

3) Citrus fruit juices: Commercially available valencia orange, lemon and kabosu juices

4) Citrus fruits: valencia orange (C. sinensis Osbeck), unshiu orange (C. unshiu Mar.), kabosu (C. sphaerocarpa Hort. ex Tanaka), buntan (C. grandis Osbeck)

Analytes:

Bergamottin, 6', 7'-dihydroxybergarnottin (DHB), 2 furanocoumarin dimers, naringin and narirutin were selected as analytes for this investigation.
DHB and 2 furanocoumarin dimers had to be prepared, because they were not available as commercial reagents. The methods to obtain these compounds by organic synthesis and purification from grapefruit oil are described as follows. Concerning the other compounds, commercial reagents of $100 \%$ purity were used.

1) Synthesis of DHB: $350 \mathrm{mg}$ bergamottin was treated with MCPBA and TFA in $\mathrm{CH}_{2} \mathrm{Cl}_{2}$. $100 \mathrm{mg}$ DHB of $92.8 \%$ purity was obtained.

2) Purification of furanocoumarin dimers: Dimer $\mathrm{A}$ (dimer of DHB) and dimer B (dimer of DHB and bergamottin) were purified from $1 \mathrm{~kg}$ of grapefruit oil by repeating $\mathrm{SiO}_{2}$ column chromatography. The yield and purity were $73 \mathrm{mg} / 58.4 \%$ and $58 \mathrm{mg} / 7.2 \%$, respectively.

\section{Pretreatment procedures:}

1) GFJ and other citrus fruit juices: $1 \mathrm{ml}$ of juice was purified by adding ethanol.

2) GF and other citrus fruits: A fruit was divided into peel, segment and pulp, and each part was grounded. $10 \mathrm{~g}$ of each grounded part was extracted by ethanol.

Determinations of chemical constituents:

The sample solutions were injected onto a reversed phase HPLC. Gradient elution system was performed with $\mathrm{CH}_{3} \mathrm{CN}$ and $10 \mathrm{mM} \mathrm{CH}_{3} \mathrm{COONH}_{4}$ (pH: 4.5). The detection was conducted with $\mathrm{UV} / 240 \mathrm{~nm}$.

\footnotetext{
* バイエル薬品侏臨床薬理

テ 532-8577 大阪市淀川区宮原 3-5-36
} 
Tab. Quantitative comparison of chemical constituents in GFJ, GF and other citrus fruits and juices

\begin{tabular}{|c|c|c|c|c|c|c|c|c|c|c|}
\hline \multirow{3}{*}{ Constituent } & \multicolumn{4}{|c|}{ Juice (mg/250 ml*) } & \multicolumn{6}{|c|}{ Fruit (mg/125 $\left.\mathrm{g}^{* *}\right)$} \\
\hline & \multirow{2}{*}{ GFJ*** } & \multirow{2}{*}{$\begin{array}{c}\text { valencia } \\
\text { orange }\end{array}$} & \multirow{2}{*}{ lemon } & \multirow{2}{*}{ kabosu } & \multicolumn{2}{|c|}{ GF } & \multirow{2}{*}{$\begin{array}{c}\text { valencia } \\
\text { orange }\end{array}$} & \multirow{2}{*}{$\begin{array}{l}\text { unshiu } \\
\text { orange }\end{array}$} & \multirow{2}{*}{ kabosu } & \multirow{2}{*}{ buntan } \\
\hline & & & & & "white" & "ruby" & & & & \\
\hline naringin & $74.6-226$ & nd & nd & 17.5 & 80.6 & 70.9 & nd & nd & 23.0 & 54.0 \\
\hline narirutin & $26.4-58.7$ & nd & nd & 57.9 & 27.4 & 30.4 & nd & nd & 66.2 & nd \\
\hline bergamottin & $1.2-4.2$ & nd & nd & nd & 1.6 & 0.9 & nd & nd & nd & nd \\
\hline DHB & $0.3-3.0$ & nd & nd & nd & 2.5 & 0.9 & nd & nd & nd & 0.1 \\
\hline $\operatorname{dimer} \mathbf{A}$ & $1.1-2.1$ & nd & nd & nd & 3.9 & 3.4 & nd & nd & nd & nd \\
\hline dimer B & $0.0-0.6$ & nd & nd & nd & 0.2 & 0.1 & nd & nd & nd & nd \\
\hline * $250 \mathrm{ml}:$ & volume as norn & nal single $\mathrm{i}$ & take & & & & & & (nd: not & detected) \\
\hline ** $\quad 125 \mathrm{~g}:$ & erage pulp we & i hat of $\mathrm{h}$ & Sut & & & & & & & \\
\hline
\end{tabular}

\section{Results}

The quantitative comparison of the chemical constituents is summarized in the above table. In GF, all tested constituents were detected in all parts (pulp, peel and segment). Flavonoids were more abundant in peel and segment than pulp.

\section{Discussion}

Though DHB and 2 furanocoumarin dimers had to be prepared when we started this investigation, they were successfully obtained by a new organic synthetic route or isolation from grapefruit oil. Also, the sensitive HPLC/UV method for tested chemical constituents was newly developed for this investigation.

Amounts of the chemical constituents of possible CYP3A4 inhibitors in a half cut of GF were similar to $250 \mathrm{ml}$ of GFJ. Therefore, the same notice with GFJ should be provided to the patients when they take the drugs which are metabolized by CYP3A4.

Total amount of furanocoumarins was only $3-8 \%$ of the total amount of flavonoids (naringin and narirutin) in GFJ and GF. On the other hand, in vitro CYP3A4 inhibitory activities of furanocoumarins are more potent than flavonoids by 40 (DHB) to $10^{4}$ (dimer A) times ${ }^{1), 3), 4), 5)}$
Therefore, furanocoumarins may play a more relevant role on the CYP3A4 inhibition. Although naringin and narirutin were detected in kabosu and buntan in similar or smaller amount compared to GF or GFJ, furanocoumarins were not detected or negligible in the tested citrus fruits and juices other than GF and GFJ. Thus, the drug interaction in terms of CYP3A4 inhibition was thought to be a specific precaution for taking GF and GFJ among citrus fruits and juices.

\section{Conclusion}

Furanocoumarins, which are reported as potent CYP3A4 inhibitors, were considered to be specific constituents in GF and GFJ among tested citrus fruits and juices. While flavonoids were detected as main constituents in GF and GFJ as well as kabosu and buntan (only naringin), they could not be detected in valencia orange, unshiu orange and lemon juice.

\section{References}

1) Fukuda, K., et al.: Pharmacogenetics, 7: 391-396 (1997).

2) Schmiedlin-Ren, P., et al.: Drug Metab. Dispos. 25: 1228-1233 (1997).

3) Edwards, D. J., et al.: Drug Metab. Dispos. 24: 12871290 (1996).

4) Fukuda, K. et al.: Biol. Pharm. Bull. 20: 560-564 (1997).

5) Taniguchi, M., et al.: The 45th Annual Meeting of the Japanese Society of Pharmacognosy (abstracts): 240 (1998). 